ARTICLE

\title{
Development of an Atmosphere-Soil-Vegetation Model for Investigation of Radioactive Materials Transport in the Terrestrial Biosphere
}

\author{
Genki KATATA $^{1, *}$, Haruyasu NAGAI ${ }^{1}$, Leiming ZHANG ${ }^{2}$, Andreas HELD ${ }^{3}$, \\ Dominique SERÇA ${ }^{4}$ and Otto KLEMM ${ }^{5}$ \\ ${ }^{1}$ Japan Atomic Energy Agency, 2-4 Shirakata, Tokai-mura, Naka-gun, Ibaraki-ken, 319-1195, Japan \\ ${ }^{2}$ Environment Canada, 4905 Dufferin St. Toronto, Ontario, M3H 5T4, Canada \\ ${ }^{3}$ Universität Bayreuth, Dr.-Hans-Frisch-Straße 1-3, Bayreuth, 95448, Germany \\ ${ }^{4}$ Laboratoire d'Aerologie, 14 Avenue Edouard Belin, Toulouse, 31400, France \\ ${ }^{5}$ Universität Münster, Robert -Koch Str. 26, Münster, 48149, Germany
}

\begin{abstract}
In order to investigate the transport of radionuclides in the terrestrial biosphere we have developed a one-dimensional numerical model named SOLVEG that predicts the transfer of water, heat, and gaseous and particulate matters in the atmosphere-vegetation-soil system. SOLVEG represents the atmosphere, the soil, and the vegetation as an aggregation of several layers. Basic equations used in the model are solved using the finite difference method. Most of the predicted variables are interrelated with the source/sink terms of momentum, water, heat, gases, and particles based on mathematically described biophysical processes in atmosphere, soil and vegetation. SOLVEG can calculate the deposition of gaseous compounds and particulates, including fog droplets, at each canopy layer. Performance tests of SOLVEG were carried out with several observational sites. SOLVEG predicted well the observed temporal changes in water vapor and $\mathrm{CO}_{2}$ fluxes, and the deposition velocity of $\mathrm{O}_{3}$ and $\mathrm{SO}_{2}$ at the vegetation surface, mainly driven by photosynthesis. SOLVEG also reproduced measured fluxes of fog droplets (diameter $>$ $1 \mu \mathrm{m}$ ) and of fine aerosols (diameter $<1 \mu \mathrm{m}$ ) over a coniferous forest.
\end{abstract}

KEYWORDS: numerical model, atmosphere, soil, vegetation, gas deposition, particle deposition, radionuclides transport

\section{Introduction}

The environmental modeling of radionuclides transport to vegetation is important when assessing the impact of radionuclides on terrestrial ecosystems. From the perspective of impacts of the nuclear fuel cycle or nuclear accidents, many process-oriented models have been developed and tested in international programs such as BIOMASS (BIOsphere Modelling and ASSessment ${ }^{1)}$ ) and EMRAS (Environmental Modelling for RAdiation Safety ${ }^{2}$ ). It is however well recognized that model predictions for environmental contamination are still associated with high uncertainties. This raises the need for development of sophisticated process-based model, as well as for an increase of appropriate data for verification of these models.

Dry and wet deposition of airborne pollutants onto the vegetation is key processes in such environmental models. The current dispersion (chemistry-transport) models used for radionuclides strongly rely on parameterizations for the processes. ${ }^{3)}$ In particular, an accurate estimation of dry deposition of gases and particles by the model is difficult as compared with the estimate of wet deposition. The process of dry deposition is driven by a variety of physical, chemical and biological factors and processes that can cause large variations in deposition on both small and large temporal

*Corresponding author, E-mail:katata.genki@jaea.go.jp

(C) 2011 Atomic Energy Society of Japan, All Rights Reserved. and spatial scales. ${ }^{4)}$ Further complications arise from the fact that radionuclides, when released into the atmosphere, exist in various chemical and physical states. For instance, it is usually assumed that most of cesium released to the atmosphere in nuclear accidents is incorporated into particles, while iodine is either bound to particles or in gaseous form (elemental form and organic iodine $\mathrm{CH}_{3} \mathrm{I}$ ). Radionuclides such as tritiated water vapor (HTO), ${ }^{14} \mathrm{CO}_{2}$ and ${ }^{14} \mathrm{CH}_{4}$ (carbon-14) that originate in the nuclear fuel cycle are also released to the atmosphere in gaseous form. A detailed process-based model that can estimate the dry deposition of both gases and particles is needed to assess the impact of radionuclides on the terrestrial biosphere.

The authors have developed a one-dimensional multi-layer numerical model that predicts the transfer of water, heat, and $\mathrm{CO}_{2}$ in the atmosphere-soil-vegetation system named SOLVEG. ${ }^{5,6)}$ Though SOLVEG is similar to other land surface models such as MATSIRO, ${ }^{7)} \mathrm{SiB} 2,{ }^{8)}$ and CASA, ${ }^{9)}$ the model has unique in representing atmosphere-soil-vegetation system as a multi-layer structure which enables to predict vertical profiles of each predicted variables. SOLVEG has been used to examine the heat and water vapor exchange of short and tall vegetation, as well as semi-arid bare soil areas. ${ }^{10-15)}$ In the present study, new schemes for calculations of dry deposition of gaseous and particulate materials onto vegetation were developed and 
incorporated into the model. Performance tests of SOLVEG are carried out through comparisons using field datasets of fluxes of gases and particles over vegetative surfaces.

\section{Numerical Model}

\section{Model Overview}

SOLVEG is a one-dimensional multi-layer model that consists of four sub-models for the atmosphere near the surface, the soil, the vegetation, and the radiation within the vegetation canopy. Figure 1 illustrates all the processes modeled in SOLVEG. Details of the model have been described by References 5 and 6 .

The atmosphere sub-model calculates variables at each atmospheric layer by numerically solving one-dimensional diffusion equations for the horizontal wind speed components, potential temperature, specific humidity, liquid water content of fog, turbulent kinetic energy and length scale, and gas and particle number concentrations. By using $\phi$ for these variables, one-dimensional diffusion equations are described in the same form as

$$
\frac{\partial \phi}{\partial t}=\frac{\partial}{\partial z} K_{z} \frac{\partial \phi}{\partial z}+F_{\phi},
$$

where $K_{z}$ is the vertical turbulence diffusivity calculated by the turbulence closure model by Yamada. ${ }^{16)}$ The last term $F_{\phi}$ is a forcing term which includes the exchange between the vegetation and canopy air as the volume source/sink for each atmospheric variable. The top boundary conditions are provided as input data. The soil surface boundary conditions are the momentum, heat, and water vapor fluxes calculated using bulk transfer equations of wind speed, potential temperature, and specific humidity at the lowest air layer and the soil surface temperature and specific humidity, which are determined with the soil sub-model.

The soil sub-model calculates the soil temperature, volumetric soil water content, and specific humidity of air in the soil pore space using a heat conduction equation, mass balance equation for liquid water, and the diffusion equation for water vapor, respectively. These three equations are closely related to each other through the phase change in water that takes place as the term of evaporation rate in the soil. The uptake of soil water by roots is derived from the rate of transpiration to the atmosphere calculated in the vegetation sub-model. At the soil surface boundary the soil sub-model can then be coupled with the atmosphere sub-model by solving the soil surface heat and water budget equations. In the soil $\mathrm{CO}_{2}$ model that is included in the soil sub-model, the diffusive and convective transport of $\mathrm{CO}_{2}$ in both aqueous and gas phases are considered in the mass conservation of $\mathrm{CO}_{2}$ for unsaturated soil.

The vegetation sub-model calculates the leaf temperature and water on the surface of leaves (leaf surface water) for each canopy layer, and the vertical liquid water flux in the entire canopy. The leaf temperature is calculated by solving the heat budget equation at the leaf surface using the leaf temperature and other variables from the atmosphere sub-model in addition to the radiation scheme. For the ver-

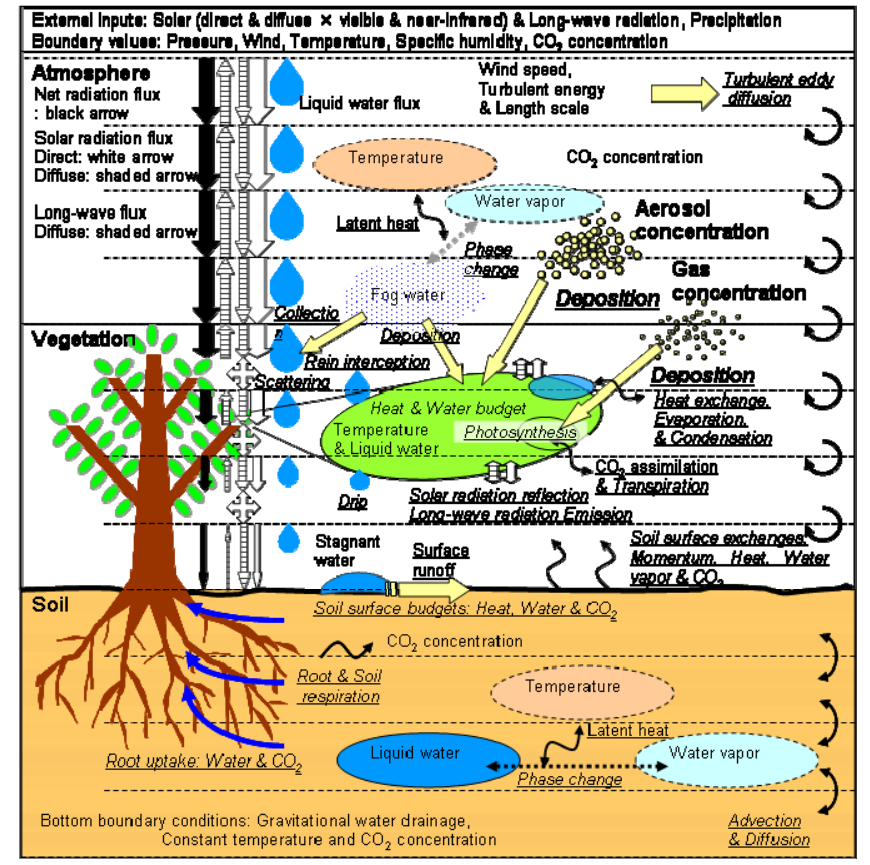

Fig. 1 Schematic illustration of modeled processes in the atmosphere-soil-vegetation system. Underlined words in boldface print are newly modeled processes in the present study.

tical liquid water flux in the canopy, the input precipitation intensity becomes the boundary value at the top of the canopy, with the value calculated for the bottom of the canopy then being available for use in the surface water budget calculation in the soil sub-model. In the vegetation sub-model, the photosynthesis is also incorporated for calculating the $\mathrm{CO}_{2}$ assimilation rate based on formulations for the relationship between the stomatal resistance and net $\mathrm{CO}_{2}$ assimilation rate.

The radiation sub-model separately calculates the direct and diffuse downward and upward fluxes of solar and long-wave radiation in the canopy and provides the radiation energy input for heat budget calculations at the soil surface and canopy layers. The leaves of each canopy layer are separated into two fractions: sunlit and shaded. The stomatal resistance and energy budget are then independently calculated for each fraction. The above-mentioned sub-models are closely related to each other, with iterative calculations being required to solve some of the equations numerically. A small value (such as several seconds) of a time step adapted for each simulation scenario is therefore used to reduce the iterations in the sub-models.

\section{Formulations for Dry Deposition Calculation}

(1) Water Vapor and $\mathrm{CO}_{2}$ Exchange over Vegetative Surfaces

Dry deposition of atmospheric gases can be formulated based on photosynthesis at plant's leaves similar to water vapor and $\mathrm{CO}_{2}$ exchanges. The modeled source/sink terms $F_{\phi}$ in Eq. (1) for water vapor and $\mathrm{CO}_{2}$ are described in the present section. A full description of formulations for photosynthesis can be found in Reference 5 .

The source/sink term for $\mathrm{CO}_{2}, F_{c 02}$, is represented as the 
aggregation of the net $\mathrm{CO}_{2}$ assimilation rate $A_{n}$ of leaves at each canopy layer as

$$
F_{c o 2}=-M_{a} a A_{n} / \rho,
$$

where $M_{a}$ is the molecular weight of air, $a$ the leaf area density, and $\rho$ the air density.

In SOLVEG, the $\mathrm{CO}_{2}$ assimilation rate and stomatal resistance are calculated based on photosynthetic process. The $\mathrm{CO}_{2}$ assimilation rate $A_{n}$, the stomatal resistance $r_{s}$, and the $\mathrm{CO}_{2}$ partial pressure of the leaf interior, $c_{i}$, are calculated by the following formulations as

$$
\begin{aligned}
& A_{n}=\min \left(w_{c}, w_{e}, w_{s}\right)-R_{d}, \\
& A_{n}=\frac{c_{a}-c_{s}}{1.37 r_{l b} p_{a}}=\frac{c_{s}-c_{i}}{1.65 r_{s} p_{a}}, \\
& \frac{1}{r_{s}}=m \frac{A_{n}}{c_{s}} \frac{e_{s}}{e_{s a t}\left(T_{c}\right)} p_{a}+g_{s \min }, \\
& \frac{e_{a}-e_{i}}{r_{l b}+r_{s}}=\frac{e_{a}-e_{s}}{r_{l b}}=\frac{e_{s}-e_{i}}{r_{s}},
\end{aligned}
$$

where $w_{c}, w_{e}$, and $w_{s}$ are the potential rate of assimilation under unlimited conditions by the photosynthetic enzyme system's (Rubisco's) efficiency, the absorbed PAR (Photosynthetically Active Radiation), and the capacity of the leaves to export the products of photosynthesis, respectively, $R_{d}$ the leaf respiration rate, $c_{a}, c_{s}, e_{s}, e_{s a t}\left(T_{c}\right)$, and $p_{a}$ the $\mathrm{CO}_{2}$ partial pressure of canopy air and that at leaf surface, vapor pressure at leaf surface, saturated vapor pressure for leaf temperature $T_{c}$, and atmospheric pressure, respectively, $e_{i}$ the vapor pressures of the leaf interior, and $e_{a}$ the canopy air. The coefficient $m$ and minimum stomatal conductance $g_{\text {smin }}$ are empirically determined from observations. $w_{c}$ and $w_{s}$ are calculated using the parameter of $V_{m 25}$ in Table 1 depending on vegetation type. ${ }^{5)} r_{l b}$ is the leaf boundary layer resistance for $\mathrm{CO}_{2}$ exchange between leaf and canopy air, which is determined from the wind speed of each canopy layer calculated by the atmosphere sub-model. Eqs. (3) and (5) are based on the formulations by Farquhar et al. ${ }^{17)}$ and Collatz et al., ${ }^{18,19)}$ respectively. Eqs. (4) and (6) are derived from resistance models for $\mathrm{CO}_{2}$ and water vapor pressure, respectively.

Equations (3) to (6) are solved iteratively to determine $r_{s}$ and $A_{n}$ for each integration time step. At first, $A_{n}$ is calculated by Eq. (3) using a initial value of $c_{i}$, and this value and $c_{a}$ are used to determine $c_{s}$ by Eq. (4). Then, $r_{s}$ and $e_{s}$ are determined by solving Eqs. (5) and (6) simultaneously. With the derived values of $A_{n}$ and $r_{s}, c_{i}$ is again calculated by Eq. (4). Using the calculated $c_{i}, A_{n}$ is recalculated by Eq. (3). This procedure is repeated until the value of $c_{i}$ converges below a specified threshold.

When the plant's leaves are not wet, the source/sink term for water vapor, $F_{q}$, is represented as the aggregation of the evaporation rate of leaf surface water, $E_{d}$, and the transpiration rate, $E_{s}$, at each canopy layer as

$$
\begin{aligned}
& F_{q}=a\left(E_{d}+E_{s}\right) / \rho, \\
& E_{s}=\rho \frac{r_{d}}{R^{\prime}}\left[q_{s a t}\left(T_{c}\right)-q_{a}\right],
\end{aligned}
$$

$$
E_{d}=\rho \frac{r_{s}}{R^{\prime}}\left[q_{s a t}\left(T_{c}\right)-q_{a}\right],
$$

where $r_{a}, r_{d}$, and $r_{s}$ are the resistances of leaf boundary layer, of evaporation of leaf surface water, and of stomata, respectively, $R^{\prime}=r_{a} r_{s}+r_{a} r_{d}+r_{s} r_{d}, q_{s a t}\left(T_{c}\right)$ the saturated specific humidity for $T_{c}$, and $q_{a}$ the specific humidity of air, respectively.

(2) Gas Deposition onto Vegetation

Atmospheric gases are vertically transported by turbulent eddy diffusion and mainly absorbed by plants due to stomata uptake at plants' leaves. Based on the analogy of evaporation rate represented as Eq. (9), the gas deposition rate, $F_{g}$, at each canopy layer is modeled using the stomatal resitance $\left(r_{s}\right)$ calculated by Eq. (5) and quasi-laminar resistance over the leaves $\left(r_{a}\right)$ as

$$
F_{g}=a\left(D_{g} / D_{w}\right)\left(r_{a}+r_{s}\right)^{-1}\left(c_{g a}-c_{g s}\right),
$$

where $D_{g}$ and $D_{w}$ are the diffusivity of trace gas and water vapor, and $c_{g a}$ and $c_{g s}$ the gas concentration around the leaf surface and within the stomata, respectively. For simplicity, the gas concentration in sub-stomatal cabity is assumed to be zero, i.e., $c_{g s}=0$.

Some of trace gases studied here, such as $\mathrm{O}_{3}$ and $\mathrm{SO}_{2}$, have also other transfer pathways to the vegetative surfaces: for example, the cuticle and wetted surfaces of leaves (especially for water-soluble compounds), the branches, the trunks, and the soil exposed to atmosphere. All of these pathways, which are often summarized as the so-called 'non-stomatal deposition', have become recognized as a sink of gases at the terrestrial surface, ${ }^{20,21)}$ but its impact on deposition onto vegetation is still unclear.

The non-stomatal deposition is so far mainly formulated based on empirical and site-specific parameterizations in current models and it is not straightforward to include it to SOLVEG mechanistically. Thus, we incorporated only the stomatal deposition into SOLVEG and evaluate its impact by comparing its calculation result with that of the commonly used model proposed by Zhang et al. ${ }^{22)}$ which includes both stomatal and non-stomatal deposition.

(3) Particle Deposition onto Vegetation

The atmosphere and vegetation sub-models include the module for the calculation of fog deposition onto the leaves based on the processes of inertial impaction and gravitational settling of particles at each vegetation layer. ${ }^{14)}$ In the present study, a novel scheme of the collection rates due to Brownian diffusion and interception, which can affect fine particles typically smaller than $0.1 \mu \mathrm{m}$ in diameter, is developed. Both processes are formulated based on semi-empirical equations obtained by wind-tunnel studies for packed fibres of a filter.

The particle deposition rate, $F_{p}$, in each canopy layer is represented as

$$
\begin{aligned}
& F_{p}=a E_{p} / \rho, \\
& E_{p}=\varepsilon F_{f}|\mathbf{u}| N_{p},
\end{aligned}
$$

where $E_{p}$ is the capture of particles by leaves, $\varepsilon$ the total capture efficiency of the plants' leaves for particles, $F_{f}$ the 
shielding coefficient for particles in horizontal direction, $|\mathbf{u}|$ the horizontal wind speed at each canopy layer, and $N_{p}$ the number concentration of particles.

Assuming that each collection mechanism acts in series, the total capture efficiency $\varepsilon$ can be expressed as

$$
\varepsilon=1-\prod_{x}\left(1-\varepsilon_{x}\right),
$$

where $x$ is the collection mechanism of inertial impaction, gravitational settling, Brownian diffusion, and interception. Since the formulations of $\varepsilon$ for inertial impaction $\varepsilon_{i m p}$ and gravitational settling $\varepsilon_{g r v}$ have been described in Reference 14 only collection efficiencies due to Brownian diffusion and interception are described below.

Fine particles smaller than some $0.1 \mu \mathrm{m}$ diffuse toward the foliar surface (Brownian diffusion), when moving along the streamline around the leaves under forced convection. The collection efficiency due to Brownian diffusion, $\varepsilon_{d f}$, is described by the following formula based on Kirsch and Fuchs $^{23)}$ as

$$
\begin{gathered}
\varepsilon_{d f}=2.7 P e^{-2 / 3}, \\
P e=\frac{|\mathbf{u}| d_{\text {trg }}}{D_{B}\left(d_{p}\right)},
\end{gathered}
$$

where $P e$ is the Peclet number, which is the product of Schmidt $(S c)$ and Reynolds number $(R e), d_{t r g}$ the characteristic length of vegetation element (e.g., needle diameter for coniferous forest), and $D_{B}\left(d_{p}\right)$ the Brownian diffusion coefficient as a function of particle diameter $d_{p}$. The value of 2.7 in Eq. (14) is an empirically determined number based on experimental measurements of filter efficiencies. Equation (14) includes both effects of convection (Re) and particle diffusion $(S c)$ and is physically more reasonable than the prior parameterizations using only $S c$ in the commonly used model such as Slinn ${ }^{24)}$ and Zhang et al. ${ }^{25)}$.

When small particles perfectly follow a streamline that happens to come within one particle radius of the foliar surface, the particle hits the leaf and is captured because of its finite size (interception). The collection efficiency due to interception, $\varepsilon_{i n}$, is expressed according to the formulation by Fuchs $^{26)}$

$$
\begin{aligned}
& \varepsilon_{\text {in }}=(1+R)-(1+R)^{-1}, \\
& R=d_{p} / d_{t r g},
\end{aligned}
$$

where $R$ is the dimensionless parameter of interception. Equation (16) is associated with theoretical solution of the particle motion equation in a potential flow assumed when any other deposition mechanisms are negligible.

\section{Numerical Scheme}

The prognostic equations for all predicted variables in the model are solved at each time step using a finite difference scheme. The basic equations of SOLVEG are based on one-dimensional advection diffusion equations, which can be written in a generalized form as

$$
\frac{\partial \phi}{\partial t}=-w \frac{\partial \phi}{\partial z}+\frac{\partial}{\partial z} K \frac{\partial \phi}{\partial z}+A \phi+F
$$

\begin{tabular}{|c|c|c|c|}
\hline Items & \multicolumn{2}{|c|}{ For gases } & For par- \\
\hline Site names & Meyrargues ${ }^{30)}$ & Kane $^{31)}$ & $\begin{array}{c}\text { Waldstei } \\
\mathrm{n}^{32-34)}\end{array}$ \\
\hline Simulation periods & $\begin{array}{c}\text { Jun. 9 28, } \\
2001\end{array}$ & $\begin{array}{c}\text { Apr. } 29 \sim \\
\text { Oct. } 23 \text {, } \\
1997\end{array}$ & $\begin{array}{l}\text { Jul. 9〜 } \\
20,2001\end{array}$ \\
\hline Soil texture & Silty-clay-loam & Clay-loam & Loam \\
\hline Plant type & $\begin{array}{l}\mathrm{C} 4 \text { grass (ma- } \\
\text { ize) }\end{array}$ & $\begin{array}{l}\text { Deciduous } \\
\text { broad-leav } \\
\text { ed }\end{array}$ & Needle \\
\hline Canopy height [m] & $0.4 \sim 1.0$ & 22.0 & 19.0 \\
\hline $\begin{array}{l}\text { Leaf Area Index } \\
\text { (LAI) }\left[\mathrm{m}^{2} \mathrm{~m}^{-2}\right]\end{array}$ & $0.8 \sim 2.7$ & $1.7 \sim 6.88$ & 6.4 \\
\hline For $\mathrm{CO}_{2}$ exchange & & & \\
\hline$V_{m 25}\left[\mu \mathrm{mol} \mathrm{m}{ }^{-2} \mathrm{~s}^{-1}\right]$ & $55^{31)}$ & 33 & 33 \\
\hline$m$ & 5.0 & 9.0 & 9.0 \\
\hline$g_{\text {smin }}\left[\mu \mathrm{mol} \mathrm{m}{ }^{-2} \mathrm{~s}^{-1}\right]$ & 0.04 & 0.01 & 0.01 \\
\hline For particles & & & \\
\hline Number of bins & - & - & 100 \\
\hline Leaf shape & - & - & Cylinder \\
\hline$d_{t r g}[\mathrm{~mm}]$ & - & - & 1.5 \\
\hline
\end{tabular}

Table 1 Vegetation parameters used in SOLVEG calculations. The parameter of $V_{m 25}$ depends on vegetation type and is used to calculate $w_{c}$ and $w_{s}$ in Eq. (3).

The model numerically solves the equation in two steps: one for the advection term with an explicit method, and the other for the rest terms with a semi-implicit method except for the forcing term,

$$
\begin{aligned}
\frac{\phi^{*}-\phi^{t}}{\delta t}= & a d v\left(\phi^{t}\right) \\
\frac{\phi^{t+\delta t}-\phi^{*}}{\delta t}= & \alpha\left[\left(\frac{\partial}{\partial z} K \frac{\partial \phi}{\partial z}\right)^{t+\delta t}+A \phi^{t+\delta t}\right] \\
& +(1-\alpha)\left[\left(\frac{\partial}{\partial z} K \frac{\partial \phi}{\partial z}\right)^{*}+A \phi^{*}\right]+F^{t} .
\end{aligned}
$$

A usual center-in-space differentiation is used for the diffusion terms with fully implicit scheme. The advection terms in basic equations are spatially discretized with the low-numerical diffusion scheme HIFI, ${ }^{27)}$ which is a hybrid scheme of FI interpolation, the first-order upwind, and second-order upwind schemes. The FI interpolation method is designed so as to maximize the accuracy without loosing the stability through the use of linear analysis. ${ }^{27)}$ Detailed descriptions of the numerical solution method can be found in References 28 and 29.

\section{Simulation Conditions}

In order to run SOLVEG, hourly data of meteorology (horizontal wind speed, air temperature and humidity, short and long wave radiation, and precipitation) and atmospheric concentrations of gases and/or particles are required to determine its upper boundary conditions. Due to the lack of the above datasets with radionuclides, comprehensive datasets including fluxes of gases (water vapor, $\mathrm{CO}_{2}, \mathrm{O}_{3}$, and $\mathrm{SO}_{2}$ ) over a maize field in France (Meyrargues) and a deciduous 
(a) Latent heat (water vapor) flux
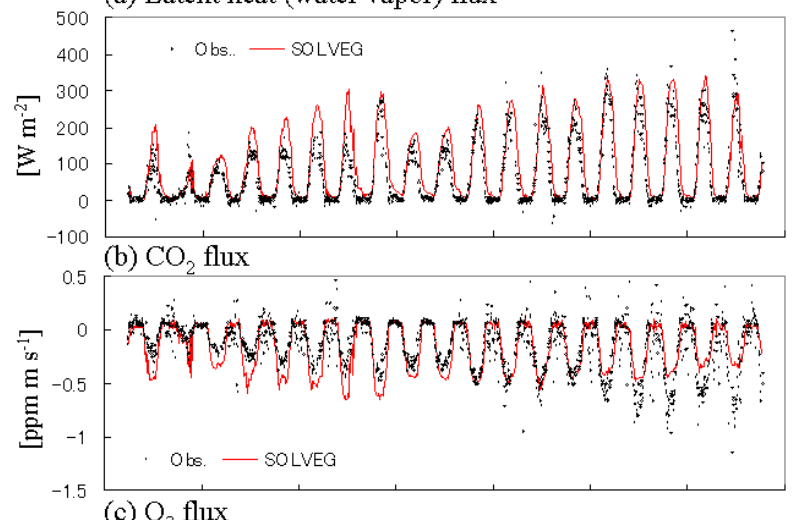

(c) $\mathrm{O}_{3}$ flux

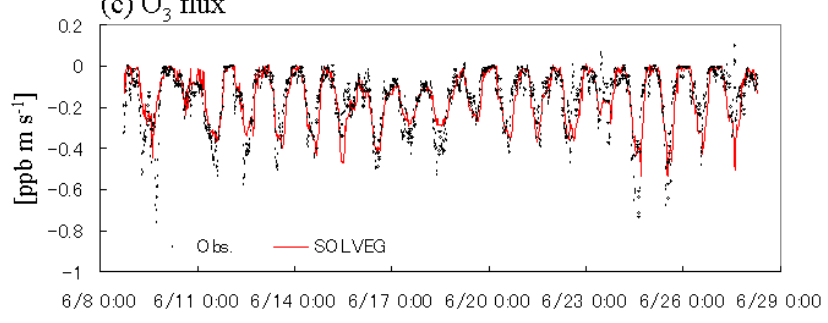

Fig. 2 Time series of calculated and observed (a) latent heat (i.e., water vapor) and (b) $\mathrm{CO}_{2}$, and (c) $\mathrm{O}_{3}$ fluxes over a maize field in France in June 2001.

broad-leaved forest in USA (Kane Experimental Forest), and those of fog droplets and fine particles over a coniferous forest in Germany (Waldstein) are used to validate the newly incorporated schemes for calculations of dry deposition. The soil temperature and the volumetric soil water content were set to be constant values as initial and lower boundary conditions. The boundaries of the atmosphere are set as heights from 0 to $3 \mathrm{~m}$ with an increment of $0.1 \mathrm{~m}$ for the maize field and from 0 to $34 \mathrm{~m}$ with an increment of $1 \mathrm{~m}$ for the forests. The boundary depths of soil are $0.02,0.05,0.1,0.2,0.5,1.0$, and $2.0 \mathrm{~m}$ for all vegetations.

The parameters used in SOLVEG are summarized in Table 1. Other parameters for each landuse category are given by Reference 5 .

\section{Results and Discussions}

\section{Gas Deposition onto the Vegetation}

Calculations by the model are compared with measurements ${ }^{30}$ of latent heat and $\mathrm{CO}_{2}$ fluxes by the eddy covariance method and deposition velocity of $\mathrm{O}_{3}$ gas measured by the gradient method over the maize field in Fig. 2. It is shown that SOLVEG predicted measured daytime upward and downward fluxes of water vapor and $\mathrm{CO}_{2}$ successfully (Figs. 2(a) and (b)). This indicates that SOLVEG can be used to simulate water vapor and $\mathrm{CO}_{2}$ fluxes predominantly originated from photosynthesis over a maize (C4 plant) field. A good performance of SOLVEG in predicting these fluxes has also been confirmed over the $\mathrm{C} 3$ grassland. ${ }^{12)}$ SOLVEG also simulated temporal changes in the measured $\mathrm{O}_{3}$ flux (Fig. 2(c)). From June 23 to 29, SOLVEG underestimated the measurements of daytime $\mathrm{CO}_{2}$ and $\mathrm{O}_{3}$ fluxes to some extent, which may be caused by the uncertainty to set the parameters of soil (e.g., unsaturated hydraulic conductivity)

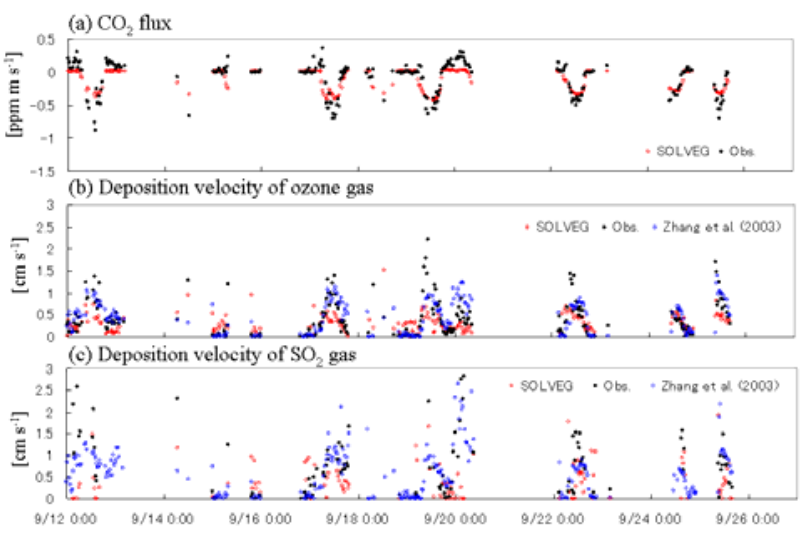

Fig. 3 Time series of calculated and observed (a) $\mathrm{CO}_{2}$ flux and deposition velocity of (b) $\mathrm{O}_{3}$ and (c) $\mathrm{SO}_{2}$ at decidous broad-leaved forest in USA on September 1997. Calculations by the model of Zhang et al. ${ }^{22)}$ are also plotted in the graph.

and vegetation (e.g., $V_{m 25}$ and $m$ ) used in the simulation. $\mathrm{O}_{3}$ uptake during the daytime by the vegetation coincided with downward $\mathrm{CO}_{2}$ flux (Figs. 2(b) and (c)). This indicates that the modeled scheme for gas absorption by stomata based on photosynthesis is reasonable and can be used to predict the gas deposition onto the crop field.

Figure 3 illustrates the temporal changes of calculations and measurements ${ }^{31)}$ in $\mathrm{CO}_{2}$ flux and deposition velocity of $\mathrm{O}_{3}$ and $\mathrm{SO}_{2}$ over the deciduous broad-leaved forest. While SOLVEG in general predicted the measured diurnal changes in gas fluxes, it underestimated measurements during the daytime for both $\mathrm{O}_{3}$ and $\mathrm{SO}_{2}$ several times. Similar to the maize field case, this discrepancy between calculations and measurements is mainly caused by the uncertainties in the model settings of soil and vegetation parameters. In addition to this, the non-stomatal deposition can affect the smaller predicted values using SOLVEG than observations in deposition velocity. In Fig. $3 \mathrm{~b}$ and $\mathrm{c}$, the calculations using the model of Zhang et al. ${ }^{22)}$ which consists of a simpler structure than SOLVEG but includes non-stomatal deposition, are plotted. It predicts a higher deposition velocity of both $\mathrm{O}_{3}$ and $\mathrm{SO}_{2}$ (Fig. 3, blue dots), which are often closer to the observations. This indicates that other pathways of gas deposition in addition to stomatal absorption may cause an under prediction of deposition velocities in SOLVEG.

Similar tendencies can be seen in averaged diurnal cycles of flux and deposition velocity of gases as shown in Fig. 4. The results again show that SOLVEG reproduced diurnal variations of deposition velocity at both maize and forest sites. However, SOLVEG underestimated the deposition velocity of both $\mathrm{O}_{3}$ and $\mathrm{SO}_{2}$ gases during daytime at the Kane forest site. The discrepancy is explained by that the model does not include non-stomatal deposition and is not optimized with vegetation parameters, as is the case of the maize field. Further, the following processes may cause the differences between observations and model predictions. For $\mathrm{O}_{3}$, there may be an increase of flux over the forest caused by the chemical reaction as $\mathrm{NO}+\mathrm{O}_{3} \rightarrow \mathrm{NO}_{2}+\mathrm{O}_{2}$ under the forest canopy when there is the emission of $\mathrm{NO}$ gas from the forest floor. This reaction can reduce the $\mathrm{O}_{3}$ concentration within the forest, resulting in an increase of $\mathrm{O}_{3}$ flux. ${ }^{36}$ ) 

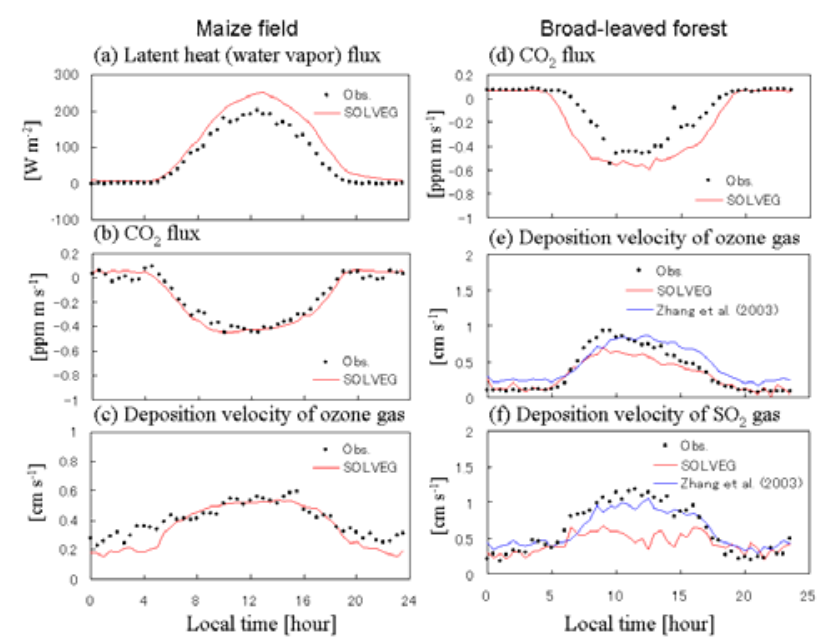

Fig. 4 Averaged diurnal cycles for the entire simulation periods of predicted and observed latent heat and $\mathrm{CO}_{2}$ fluxes and deposition velocity of $\mathrm{O}_{3}$ and $\mathrm{SO}_{2}$ at the maize and deciduous broad-leaved forest. Calculations by the model of Zhang et al. ${ }^{22)}$ are also plotted in the graph.

For $\mathrm{SO}_{2}$, the presence of water at foliar surfaces due to rain may increase its deposition velocity since $\mathrm{SO}_{2}$ can be readily dissolved with the water surface. It is known that deposition velocity of the studied gases onto the wet canopy is large compared with the dry canopy at the study area. ${ }^{37)}$ The effect of non-stomatal deposition should be investigated by further model simulations.

\section{Particle Deposition onto the Vegetation}

Calculations of turbulent fluxes of fog droplets $\left(d_{p}>\right.$ $5 \mu \mathrm{m})$ and fine particles $\left(11 \mathrm{~nm}<d_{p} \leq 0.9 \mu \mathrm{m}\right.$ and $3 \mathrm{~nm}<d_{p}$ $\leq 11 \mathrm{~nm}$ ) over the coniferous forest by SOLVEG are compared with measurements ${ }^{32-34)}$ by the eddy covariance method in Fig. 5. The fluxes calculated by the size-resolved particle deposition model of Zhang et al. ${ }^{25)}$ were larger than the measured ones. In contrast, computations by SOLVEG agreed with the observations of these fluxes. This indicates that the formulation of collection efficiency used in this study is reasonable in prediction of particle deposition onto the vegetation.

Feeding SOLVEG with a hypothetical uniform number concentration over the entire particle size range, the deposition velocities of particles over the coniferous forest in Germany was calculated with SOLVEG for each size bin. Figure 6 shows the comparisons of size-resolved deposition velocities calculated with SOLVEG and observations from the literature obtained at various coniferous forests. The model predictions by SOLVEG agreed better with measurements of deposition velocity for the large $(>1 \mu \mathrm{m})$ and small particles $(<0.1 \mu \mathrm{m})$ for some datasets than other particle deposition models.

For particles with a diameter ranging from $0.01-1 \mu \mathrm{m}$, the observed values of deposition velocity have a large uncertainty associated with the difference of environmental factors from various datasets. This makes it difficult to evaluate the model in the size range. Nevertheless, the calculations of deposition velocity seem to be significantly smaller than the (a) Turbulent fog water flux (particle diameter: $5 \sim 30 \mu \mathrm{m}$ )

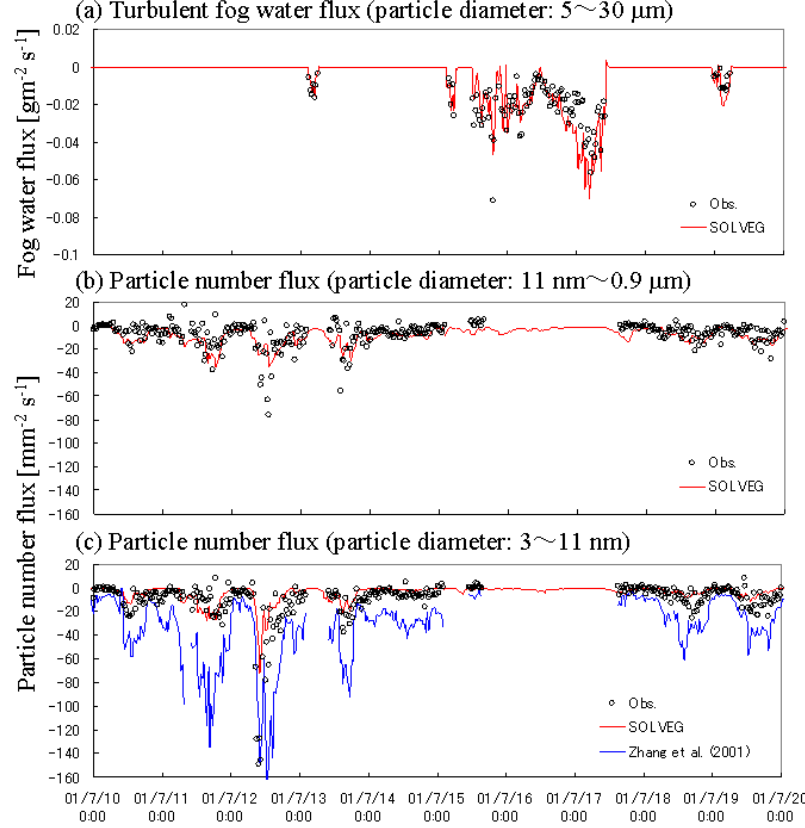

Fig. 5 Time series of calculated and observed (a) fog water flux and (b) aerosol number fluxes with particle diameters from $11 \mathrm{~nm}$ to $0.9 \mu \mathrm{m}$ and (c) from 3 to $11 \mathrm{~nm}$ over a coniferous canopy in Germany in July 2001. Calculations by the model of Zhang et al. ${ }^{25)}$ are also plotted in the graph.

measured values. This particle size range includes the crucial radionuclides such as cesium and particulate iodine, ${ }^{38,39)}$ as well as the major atmospheric organic (e.g., black carbon) and inorganic compounds (e.g., sulfates and nitrates). As suggested by Reference 40 . the processes of particle collection, such as hygroscopic particle growth, electrostatic forces, and thermo- and diffusio-phoresis, may affect the deposition velocity at this range. On the other hand, it has been hypothesized that the large measured deposition velocities in this size range may have been caused by heterogeneous processes between gases and particles as $\mathrm{NH}_{4} \mathrm{NO}_{3}$ (aerosol) $\leftrightarrow \mathrm{HNO}_{3}$ (gas) $+\mathrm{NH}_{3}$ (gas), ${ }^{41)}$ which are not included in any of the particle deposition models. These effects should be incorporated into the model and evaluated in the future.

\section{Conclusion}

New schemes for calculations of the dry deposition of gaseous and particulate materials onto vegetation were developed and incorporated into a one-dimensional multi-layer atmosphere-soil-vegetation model (SOLVEG). Dry deposition of atmospheric gases was formulated based on the schemes that calculate photosynthesis of plants and root uptake from the soil. For particle deposition, the scheme of collection efficiencies of plants' leaves due to Brownian diffusion and interception was developed to calculate the dry deposition of large and small particles. SOLVEG modified to include the schemes of gases and particle deposition was tested using comprehensive datasets including flux of gases and particles obtained over a maize field and forests at three observational sites. A good agreement in fluxes of water vapor, $\mathrm{CO}_{2}$, and $\mathrm{O}_{3}$ was shown between the model calcula- 


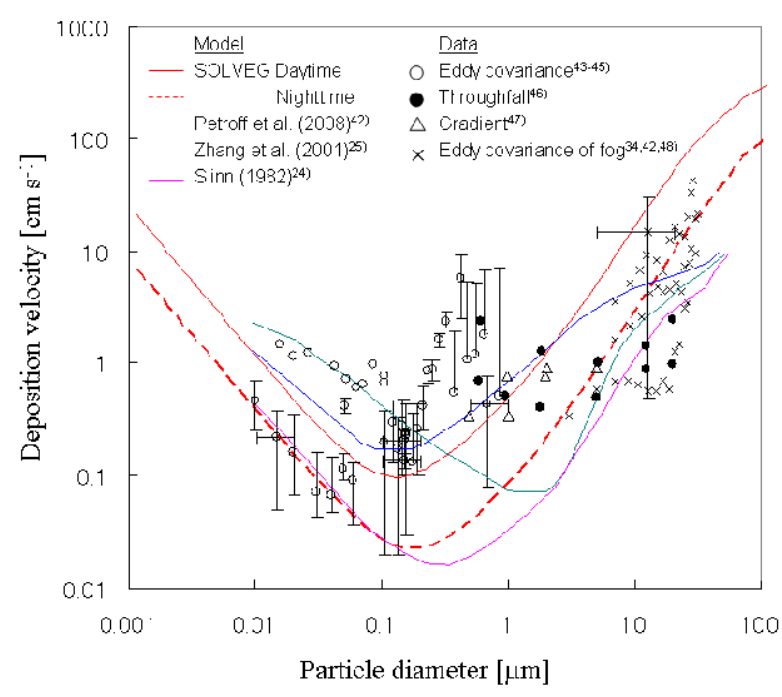

Fig. 6 Deposition velocity of aerosols and fog droplets onto coniferous forest canopies against the particle diameter, as given by measurements obtained by eddy covariance, throughfall, and gradient methods, and by SOLVEG and three other particle deposition models.

tions and observations over the vegetation. SOLVEG also predicted the measured fluxes from nano- to micrometer-sized particles over the forest. The results suggest the effects of wet canopy, hygroscopic particle growth, electrostatic forces, thermo- and diffusio-phoresis, and heterogeneous chemical reactions on dry deposition should be investigated.

\section{Acknowledgment}

The authors wish to express their gratitude to two reviewers of the paper. The present study was partially supported by the Ministry of Education, Culture, Sports, Science and Technology, the Grant-in-Aid for Scientific Research on Innovative Areas (21120512) and for Young Scientists B (21710035).

\section{References}

1) IAEA (International Atomic Energy Agency), Modelling the environmental transport of tritium in the vicinity of long term atmospheric and sub-surface sources, Report of the Tritium Working Group of the Biosphere Modelling and Assessment (BIOMASS) Programme Thema 3 (2003).

2) EMRAS Working Group Report (draft), http://www-ns.iaea.org/downloads/rw/projects/emras/draft-fin al-reports/emras-tritium-wg.pdf

3) B. Sportisse, "A review of parameterizations for modelling dry deposition and scavenging of radionuclides," Atmos. Environ., 41[13], 2683-2698 (2007).

4) Z. Ould-Dada, D. Copplestone, M. Toal, G. Shaw, "Effect of forest edges on deposition of radioactive aerosols," Atmos. Environ., 36[36-37], 5595-5606 (2002).

5) H. Nagai, Atmosphere-soil-vegetation model including $\mathrm{CO}_{2}$ exchange processes: SOLVEG2, JAERI-Data/Code 2004-014, Japan Atomic Energy Agency (JAEA) (2004).

6) G. Katata, Improvement of a land surface model for accurate prediction of surface energy and water balances, JAEA-Data/Code 2008-033, Japan Atomic Energy, Agency (JAEA) (2009).

7) K. Takata, S. Emori, T. Watanabe, "Development of the minimal advanced treatments of surface interaction and runoff," Global Planet. Change, 38[1-2], 209-222 (2003).

8) P. J. Sellers, D. A. Randall, G. J. Collatz, J. A. Berry, C. B. Field, D.A. Dazlich, C. Zhang, G. D. Collelo, L. Bounoua, "A revised land surface parameterization $(\mathrm{SiB} 2)$ for atmospheric GCMS. Part I: Model formulation," J. Climate, 9[4], 676-705 (1996).

9) C. S., Potter, J. T. Randerson, C. B. Field, P. A. Matson, P. M. Vitousek, H. A. Mooney, S. A. Klooster, "Terrestrial ecosystem production: A process model based on global satellite and surface data," Global Biogeochem. Cycles, 7[4], 811-841 (1993).

10) H. Nagai, "Validation and sensitivity analysis of a new atmosphere-soil-vegetation model," J. Appl. Meteorol., 41[2], 160-176 (2002).

11) H. Nagai, "Validation and sensitivity analysis of a new atmosphere-soil-vegetation model. Part II: Impacts on in-canopy latent heat flux over a winter wheat field determined by detailed calculation of canopy radiation transmission and stomatal resistance," J. Appl. Meteorol., 42[3], 434-451 (2003).

12) $\mathrm{H}$. Nagai, "Incorporation of $\mathrm{CO}_{2}$ exchange processes into a multilayer atmosphere-soil-vegetation model," J. Appl. Meteorol., 44[10], 1574-1592 (2005).

13) G. Katata, H. Nagai, H. Ueda, N. Agam, P. R. Berliner, "Development of a land surface model including evaporation and adsorption processes in the soil for the land-air exchange in arid regions," J. Hydrometeorol., 8[6], 1307-1324 (2007).

14) G. Katata, H. Nagai, T. Wrzesinsky, O. Klemm, W. Eugster, R. Burkard, "Development of a land surface model including cloud water deposition on vegetation," J. Appl. Meteorol. Climatol., 47[8], 2129-2146 (2008).

15) G. Katata, H, Nagai, M. Kajino, H. Ueda, Y. Hozumi, "Numerical study of fog deposition on vegetation for atmosphere-land interactions in semi-arid and arid regions," Agr. Forest Meteorol., 150[3], 340-353 (2010).

16) T. Yamada, "A numerical model study of turbulent airflow in and above a forest canopy," J. Meteor. Soc. Japan, 60[1], 439-454 (1982).

17) G. D. Farquhar, P. M. Firth, R. Wetselaar, B. Weir, "On the gaseous exchange of ammonia between leaves and the environment: determination of the ammonia compensation point," Plant Physiol., 66[4], 710-714 (1980).

18) G. J. Collatz, J. T. Ball, C. Grivet, J. A. Berry, "Physiological and environmental regulation of stomatal conductance, photosynthesis and transpiration: a model that includes a laminar boundary layer," Agr. Forest Meteorol., 54[2-4], 107-136 (1991).

19) G. J. Collatz, M. Ribas-Carbo, J. A. Berry, "Coupled photosynthesis-stomatal conductance model for leaves of $\mathrm{C} 4$ plants," Aust. J. Plant Physiol, 19[5], 519-538 (1992).

20) D. Fowler, C. Flechard, J. N. Cape, R. L. Storeton-West, M. Coyle, "Measurements of ozone deposition to vegetation quantifying the flux, the stomatal and non-stomatal components," Water Air Soil Pollut., 130[1-4], 63-74 (2001).

21) M. Coyle, E. Nemitz, R. Storeton-West, D. Fowler, J. N. Cape, "Measurements of ozone deposition to a potato canopy," Agr. Forest Meteorol., 149[3-4], 655-666 (2009).

22) L. Zhang, J. R. Brook, R. Vet, "A revised parameterization for 
gaseous dry deposition in air-quality models," Atmos. Chem. Phys., 3, 2067-2082 (2003).

23) A. A. Kirsch, N. A. Fuchs, "Studies on fibrous aerosol filters. III . Diffusional deposition of aerosols in fibrous filters," Ann. Occup. Hyg., 11[4], 299-304 (1968).

24) W. G. N. Slinn, "Predictions for particle deposition to vegetative canopies," Atmos. Environ., 16[7], 1785-1794 (1982).

$25)$ L. Zhang, S. Gong, J. Padro, L. Barrie, "A size-segregated particle dry deposition scheme for an atmospheric aerosol module," Atmos. Environ., 35[3], 549-560 (2001).

26) N. A. Fuchs, The Mechanics of Aerosols. Pergamon Press, Oxford (1964).

27) H. Yamazawa, "Development of a numerical solution method for advection terms and its application to the atmospheric dynamic model, PHYSIC," J. Nucl. Sci. Technol., 33[1], 69-77 (1996).

28) H. Yamazawa, H. Nagai, Development of one-dimensional atmosphere-bare soil model, JAERI-Research 97-041, Japan Atomic Energy Research, Institute (JAERI) (1997), [in Japanese].

29) H. Nagai, H. Yamazawa, Development of one-dimensional atmosphere-soil-vegetation model, JAERI-Data/Code 99-024, Japan Atomic Energy Research Institute (JAERI) (1999), [in Japanese].

30) M. Michou, P. Laville, D. Serça, A. Fotiadi, P. Bouchou, V.-H. Peuch, "Measured and modeled dry deposition velocities over the ESCOMPTE area," Atmos. Res., 74[1-4], 89-116 (2005).

31) P. L. Finkelstein, T. G. Ellestad, J. F. Clarke, T. P. Meyers, D. B. Schwede, E. O. Herbert, J. F. Neal, "Ozone and sulfur dioxide dry deposition to forests: Observations and model evaluation," J. Geophys. Res., 105D[12], 15365-15377 (2000).

32) A. Held, O. Klemm, "Direct measurement of turbulent particle exchange with a twin CPC eddy covariance system," Atmos. Environ., 40[S1], 92-102 (2006).

33) A. Held, A. Nowak, A. Wiedensohler, O. Klemm, "Field measurements and size-resolved model simulations of turbulent particle transport to a forest canopy," J. Aerosol Sci., 37[6], 786-798 (2006).

34) O. Klemm, T. Wrzesinsky, "Fog deposition fluxes of water and ions to a mountainous site in Central Europe," Tellus, B59[4], 705-714 (2007).

35) W. Larcher, Ökophysiologie der Pflanzen, Eugen Ulmer, Stuttgart (2001).

36) J. N. Cape, R. Hamilton, M. R. Heal, "Reactive uptake of ozone at simulated leaf surfaces: Implications for 'non-stomatal' ozone flux," Atmos. Environ., 43[5], 1116-1123 (2009).
37) L. Zhang, J. R. Brook, R. Vet, "On ozone dry deposition-with emphasis on non-stomatal uptake and wet canopies," Atmos. Environ., 36[30], 4787-4799 (2002).

38) J. Brandt, J. H. Christensen, L. M. Frohn, "Modelling transport and deposition of caesium and iodine from the Chernobyl accident using the DREAM model," Atmos. Chem. Phys., 2, 397-417 (2002).

39) A. C. Chamberlain, Radioactive Aerosols, University Press, Cambridge (1991).

40) J. A. Garland, "On the size dependence of particle deposition," Water Air Soil Pollut., Focus 1[5-6], 323-332 (2001).

41) E. Nemitz, G. J. Phillips, C. F. Di Marco, J. Ryder, M. A. Sutton, A. Frumau, P. A. C. Jongejan, K. R. Wichink, A. Stolk, "Study of $\mathrm{NH}_{3}-\mathrm{HNO}_{3}-\mathrm{NH}_{4} \mathrm{NO}_{3}$ chemistry above a Dutch forest through size- and composition resolved aerosol fluxes", Abstracts of 2010 International Aerosol Conference, Aug. 29-Sept. 3, 2010, Helsinki, Finland, P2I4 (2010), [Available online].

42) A. Petroff, A. Mailliat, M. Amielh, F. Anselmet, "Aerosol dry deposition on vegetative canopies. Part II: A new modelling approach and applications," Atmos. Environ., 42[16], 3654-3683 (2008)

43) M. W. Gallagher, K. M. Beswick, T. W. Choularton, J. Duyzer, H. Westrate, P. HummelshøJ, "Measurements of aerosol fluxes to speulder forest using a micrometeorological technique," Atmos. Environ., 31[3], 359-373 (1997).

44) S. C. Pryor, M. Gallagher, H. Sievering, S. E. Larsen, R. J. Barthelmie, F. Birsan, E. Nemitz, J. Rinne, M. Kulmala, T. Groenholm, R. Taipale, T. Vesala, "A review of measurement and modelling results of particle atmosphere-surface exchange," Tellus, B60[1], 42-75 (2008).

45) T. Grönholm, S. Launiainen, L. Ahlm, E. Mårtensson, M. Kulmala, T. Vesala, E. Nilsson, "Aerosol particle dry deposition to canopy and forest floor measured by two-layer eddy covariance system," J. Geophys, Res., 114[D4], D04202 (2009).

46) A. Waraghai, G. Gravenhorst, "Dry deposition of atmospheric particles to an old spruce stand," In W. Georgii (ed.) "Mechanisms and Effects of Pollutant-transfer into Forests," Kluwer Academic, Dordrecht, 77-86 (1989).

47) R. Lorenz, C. E. Murphy, "Dry deposition of particles to a pine plantation," Boundary-Layer Meteorol., 46[4], 355-366 (1989).

48) K. M. Beswick, K. J. Hargreaves, M. W. Gallagher, T. W. Choularton, D. Fowler, "Size-resolved measurements of cloud droplet deposition velocity to a forest canopy using an eddy correlation technique," Q. J. Roy. Meteorol. Soc., 117[499], 623-645 (1991). 